\title{
Needle age dependence of photosynthesis along a light gradient within an Abies alba crown
}

\author{
Piotr Robakowski ${ }^{1,2} \cdot$ Ernest Bielinis ${ }^{1,2}$
}

Received: 12 September 2016/Revised: 14 November 2016/ Accepted: 12 February 2017/Published online: 23 February 2017

(C) The Author(s) 2017. This article is published with open access at Springerlink.com

\begin{abstract}
Age and shade effects on needle structure and photosynthesis were determined within a lower part of Abies alba crown along a horizontal increasing gradient of branches self-shading. It was hypothesized that a decrease in net $\mathrm{CO}_{2}$ assimilation rate with increasing needles' age would be related to: (1) structural age-related changes in needles, (2) reduction of stomatal conductance, (3) nitrogen translocation from old to young needles, and (4) decrease in efficiency of photochemical processes. Leaf mass-to-area ratio increased non-linearly with needle age. In a needle cross section, distance between the vascular bundles decreased, and height of palisade parenchyma cells increased with age. The structural changes observed in our study might lead to an increase in internal resistance to $\mathrm{CO}_{2}$ with greater needle age. Total needle nitrogen concentration linearly decreased with age due to dilution and/ or translocation to younger needles. When expressed per needle area, nitrogen content was reduced in 6-year-old needles compared with younger ones. Net $\mathrm{CO}_{2}$ assimilation rate per needle area decayed and was accompanied by a decrease in transpiration and water and photosynthetic nitrogen use efficiency. Old needles maintained high photochemical efficiency which compensated to some extent for light deficit in their micro-light environments. Our
\end{abstract}

Communicated by U. Feller.

Piotr Robakowski

pierrot@up.poznan.pl

1 Department of Forestry, Poznan University of Life Sciences, Wojska Polskiego 71E St., 60-625 Poznan, Poland

2 Unit of Forestry and Forest Ecology, Department of Environmental Management and Agriculture, University of Warmia and Mazury in Olsztyn, PL Lodzki 2, 10-727 Olsztyn, Poland results have suggested that there is a mechanism controlling the relation between efficiency of light and dark photosynthetic processes along the needle age and shade gradient in A. alba crown.

Keywords Chlorophyll $a$ fluorescence $\cdot$ Leaf age $\cdot$ Needle structure $\cdot$ Nitrogen concentration $\cdot$ Photosynthesis $\cdot$ Silver fir
Abbreviations
E Transpiration rate $\left(\mathrm{mmol} \mathrm{m} \mathrm{m}^{-2} \mathrm{~s}^{-1}\right)$
ETR $_{\text {max }} \quad$ Apparent maximum electron transfer rate $(\mu \mathrm{mol}$
$\mathrm{m}^{-2} \mathrm{~s}^{-1}$ )
$F_{\mathrm{v}} / F_{\mathrm{m}} \quad$ Maximum quantum yield of PSII
photochemistry
$\Phi_{\text {PSII }} \quad$ Quantum yield of PSII photochemistry
$\Phi_{\text {PPFDsat }}$ Quantum yield of PSII photochemistry at saturation photosynthetic photon flux density
$g_{\mathrm{s}} \quad$ Stomatal conductance $\left(\mu \mathrm{mol} \mathrm{m} \mathrm{m}^{-2} \mathrm{~s}^{-1}\right)$
LMA Leaf mass-to-area ratio $\left(\mathrm{g} \mathrm{m}^{-2}\right)$
NPQ Non-photochemical quenching of fluorescence
$P \quad$ Net $\mathrm{CO}_{2}$ assimilation rate per needle area $(\mu \mathrm{mol}$ $\mathrm{m}^{-2} \mathrm{~s}^{-1}$ )
PNUE Photosynthetic nitrogen use efficiency ( $\mu \mathrm{mol}$ $\mathrm{CO}_{2} \mathrm{~g}^{-1} \mathrm{~N} \mathrm{~s}^{-1}$ )

\section{Introduction}

The life strategy of evergreen conifer trees consists in long needle retention evolved in boreal or montane climate characterized by low temperatures, short growing season and poor soil conditions. Extended needle retention in Scots pine and Norway spruce populations in lowtemperature habitats appears to be largely an 
environmentally phenotypic acclimation (Reich et al. 1996). The major advantages of evergreen leaves compared with deciduous leaves are: longer photosynthetic season, lower amortized costs of leaf construction, lower amount of nutrients that must be absorbed each year from the soil, and tougher laminae that can better endure frosts, drought and herbivore attack (Givinish 2002). However, many authors have shown that net $\mathrm{CO}_{2}$ assimilation rates decrease with needle aging in the conifer species, e.g.: in Abies concolor Lindl. and Gord., Pinus ponderosa Laws., Pinus nigra Arnold, Pinus strobus L., Picea pungens Engelm. (Freeland 1952), Picea abies (L.) Karst. (Weikert et al. 1989), Pinus sylvestris L. (Freeland 1952; Wang et al. 1995; Jach and Ceulemans 2000), Abies amabilis (Dougl.) Forbes (Brooks et al. 1996), Pinus heldreichii Christ (Oleksyn et al. 1997), Pinus taeda L. (Crous and Ellsworth 2004), Pinus pinaster Aiton (Warren 2006), Pinus densiflora Sieb. et Zucc. (Han et al. 2008). Except for Brooks et al. the authors, generally, did not separate the light effect along the gradient in the crown from the age effect. A balance between the costs and benefits of needles construction, defense mechanisms and their long retention compared with broadleaved deciduous trees has remained an intriguing research subject.

Conifers have developed structural and physiological patterns in needles, which allow them to photosynthesize during the whole year. These adaptations are changing with needle age (Kivimäenpää and Sutinen 2007; Wyka et al. 2008). Thanks to thick epidermis, waxes layer, hypodermis, and tracheid needles are generally more tolerant to drought and other abiotic and biotic stressors than leaves of broadleaf deciduous trees (Givinish 2002). Winter photoinhibition and short-lasting stress-induced PSII downregulation have been considered as physiological needle defense mechanism (Adams et al. 2004). Under low temperature and sunny days, this is accompanied by a transient reduction of chlorophyll concentration and an increase in carotenoids, mainly xanthophylls allowing evergreen conifers to dissipate excess energy as heat and maintain photosynthetic functions (Adams and Demmig-Adams 1994; Anderson et al. 1997). However, there is little information about an effect of aging on photoprotective mechanisms and needle photochemistry (Weikert et al. 1989; Gielen et al. 2000). Here, we investigated age-related changes in photochemical functions of Abies alba needles.

Leaf aging is a complex phenomenon aggregating different processes at the molecular, physiological and structural level. Long-lived conifer trees from the genus Picea and Pinus have often been used to study needle age effects on photosynthesis (Kayama et al. 2007; Han et al. 2008 and the citations above). In contrast, little attention has been paid to the research of the genus Abies (Freeland 1952; Brooks et al. 1996).
Kayama et al. (2007) have found that in five species from the genus Picea high growth rates are related with high net $\mathrm{CO}_{2}$ assimilation rates in young needles, high needle nitrogen concentration and short needle life spans. In contrast, four other Picea species with low growth and photosynthetic rates showed inverse relation between needle age, nitrogen concentration and photosynthetic nitrogen use efficiency (PNUE, $\mu \mathrm{mol} \mathrm{m} \mathrm{m}^{-2} \mathrm{~s}^{-1}$ ). Slowgrowing species including silver fir have long-lived needles with lower photosynthetic capacity than fast-growing species with short-lived needles, but they can maintain assimilatory functions over longer periods. Moreover, PNUE is higher in fast-growing species compared with slow-growing species, but the species having long needle life span can maintain a high PNUE in older needles.

Much less is known about a variation of structural traits and physiological functions in needles within a crown of an individual evergreen conifer tree. The relation between the needle traits and their age has rarely been studied in more than three needle age classes along a light gradient within an individual tree crown (Brooks et al. 1996; Oleksyn et al. 1997). Leaf mass-to-area ratio (LMA), which has often been used as an indicator of variation in leaf structure, depended on species, light environment and leaf life span (Reich et al. 1998). Generally, LMA is higher in conifers compared with the other functional groups of plants and increased with leaf age. The physiological leaf traits such as net $\mathrm{CO}_{2}$ assimilation rate $(P)$, dark respiration $\left(R_{\mathrm{d}}\right)$, and nutrients' content in leaf are closely related to LMA (Reich et al. 1998; Wright et al. 2004).

The striking adaptation to low nutrients availability appears to be a retranslocation of nitrogen, phosphorous, potassium and other nutrients from old to young needles and other growing organs (Nambiar and Fife 1991). In A. alba $\mathrm{N}, \mathrm{P}, \mathrm{K}$, and $\mathrm{Mg}$ decreased exponentially, whereas $\mathrm{Ca}$, $\mathrm{Mn}$ and $\mathrm{Zn}$ increased exponentially with needles' age (Szymura 2009). Long needles' retention is not for freesome amount of resources is used to maintain old needles despite that photosynthetic activity of needles decreases with their increasing age. Old needles can have relatively high respiration rate and their low net $\mathrm{CO}_{2}$ assimilation rate does not compensate for a use of water, nitrogen and other resources related with needle maintenance. Therefore, the question can be addressed about the role of structural and physiological changes in needles with their increasing age in the carbon balance of an individual tree.

In this study, needle structure, photosynthesis and nitrogen content were investigated as a function of needle age along the light gradient within a bottom A. alba crown. The needle structure was described using LMA and anatomical traits. Net $\mathrm{CO}_{2}$ assimilation rate, chlorophyll $a$ fluorescence, and nitrogen content in needles were determined to compare differences in photosynthetic capacity among seven needle age 
classes. It was assumed that net $\mathrm{CO}_{2}$ assimilation rate would decrease with increasing needle age as it was shown for other species. However, the mechanisms of net $\mathrm{CO}_{2}$ assimilation rates reduction in function of needle age have only partly been elucidated. In particular, it is difficult to separate needle acclimation to self-shading with increasing needle age from effects of senescence on photosynthesis. We tested the hypothesis that a reduction of net $\mathrm{CO}_{2}$ assimilation rates and photosynthetic resources use efficiency with increasing needle age would result from increase in LMA (Wright et al. 2004; Han et al. 2008), anatomical age-related changes in needles (Miyazawa and Terashima 2001), decrease in stomatal conductance, nitrogen concentration (Brooks et al. 1996; Han et al. 2008), and efficiency of PSII photochemistry. Additionally, we posited that there would be a trade-off between efficiency of light and dark photosynthetic processes along the needle age and shade gradient in A. alba crown.

\section{Materials and methods}

\section{Material}

An individual 20-year-old A. alba Mill. tree was chosen in the Dendrological Garden of Poznan Life Sciences University (N 52 $25.572^{\prime}$; E 16 $53.650^{\prime}, 73 \mathrm{~m}$ a.s.1.). The study tree was growing under a low shade of crowns of other trees (canopy openness was 80\%). The soil was sandy. Slightly loamy sand and very loamy sand with $\mathrm{pH}$ 5.0-6.0 predominate in soil profile. A humus layer of $15 \mathrm{~cm}(\mathrm{pH} \approx 4.5)$ was composed of decayed grass roots and leaves of broadleaf and conifer trees. The type of soil was defined as anthropogenic rusty soil (Sienkiewicz 1997, unpublished). Our study tree was growing closely to three other A. alba trees being at the same age and it was representative for this group of trees with regard to age, size, and number of needle age classes. The tree height was $8.8 \mathrm{~m}$ and d.b.h. was $13.7 \mathrm{~cm}$. The selected individual was characterized by a long crown (4/5 of a tree height) with ten needle age classes. All needle age classes were represented in the bottom part of the crown. To sample needles, five shoots from two neighboring whorls at a height of $1.5 \mathrm{~m}$ were selected in the lower part of crown exposed to south. The shoots with the highest number of needle age classes compared with other shoots in the upper crown were used. The needle samples were collected from a central part of each annual shoot increment from the 1- to 7-year-old shoot increment.

\section{Light measurements}

In July, on cloudy day, relative photosynthetic photon flux (rPPFD) was determined along the chosen shoots using two quantum meters (Spectrum Technologies, Inc., Plainfield, USA). PPFD was measured simultaneously above a central part of each shoot increment and in an adjacent outside location. The relative values were determined with the following formula: (PPFD above shoot increment/PPFD in the open) $\times 100$ and the mean rPPFD values were calculated from five measurements and given in percent for each needle age class.

\section{Needle sampling}

At the end of July, within 5 days, 25 needles were randomly collected from each age class and each of the five shoots. The average temperature during the needle sampling was around $22{ }^{\circ} \mathrm{C}$ and the temperature in the laboratory was around $23{ }^{\circ} \mathrm{C}$. Needles were detached gently from a twig and enclosed into Eppendorf's tubes with a scrap of moist filter paper. After accomplished gas exchange measurements, the needles' projected area was measured using a scanner and imageJ. Next, the needles were dried at $65{ }^{\circ} \mathrm{C}$ within a week and weighed. LMA was calculated dividing needle dry mass per needle area and needle water content subtracting needle dry mass from needle fresh mass. To measure chlorophyll $a$ fluorescence, three needles from each increment were used. The needles for water content determination, microscopic observations and nitrogen concentration analyses were collected from the central part of the same shoots.

\section{Measurements of gas exchange}

Net $\mathrm{CO}_{2}$ assimilation rate $(P)$, transpiration $(E)$, and stomatal conductance $\left(g_{\mathrm{s}}\right)$ in $A$. alba needles were measured in laboratory using LCA 4 open gas exchange system (ADC Ltd., Hoddesdon, UK). Needles from one randomly chosen shoot increment (one age class) were carried into the laboratory within $5 \mathrm{~min}$. Seven samplings coordinated with the gas exchange measurements were accomplished within a day. The needles were put on a frame made of a thin cupper wire and immediately introduced into the conifer chamber (PLC4C) for acclimation prior to the gas exchange measurements. We observed that $P$ of detached 1-year-old $A$. alba needles did not significantly differ from $P$ of attached 1-year-old needles. This observation is consistent with the results of gas exchange measurements on attached and detached needles of other conifer tree species (Oleksyn et al. 1997; Maier et al. 2002). A custom-made lamp consisting of sets of interspersed blue and red diodes was used as a cool light source with intensity controlled at the power adapter (Wyka et al. 2008). Light intensity at needle surface was fixed at $400 \mu \mathrm{mol} \mathrm{m} \mathrm{m}^{-2} \mathrm{~s}^{-1}$ PPFD. Relatively low PPFD was applied to avoid photoinhibition in old needles. Carbon dioxide reference was established at 
$360 \mu \mathrm{mol} \mathrm{mol}{ }^{-1}$ and flow rate at $300 \mu \mathrm{mol} \mathrm{mol}^{-1}$. Mean $( \pm \mathrm{SE})$ needle temperature measured with a thermocouple inside the conifer chamber was $29.6 \pm 2.3{ }^{\circ} \mathrm{C}$ and relative air humidity was $54 \pm 5 \%$. Needles were acclimated into the conifer chamber microclimate within $35 \mathrm{~min}$ and all gas exchange parameters were registered in 1-min intervals. Usually, after this period all parameters were stable. The last five values of $P, E$, and $g_{\mathrm{s}}$ were used to calculate the means for each needle age class. Net $\mathrm{CO}_{2}$ assimilation rate was expressed per needle area $(P)$ and nitrogen content. Water use efficiency $(P / E)$ was calculated as net $\mathrm{CO}_{2}$ assimilation rate to transpiration ratio.

\section{Microscopic observations}

Needles for microscopic observation were sampled in the same way as for gas exchange measurements. Five needles from each age class were used for a cross-cuts preparation. The needles enclosed in Eppendorf's tubes and in a volume were transported into the Laboratory of General Botany, the Adam Mickiewicz University of Poznan. Needles were fixed in FAA (formaline $40 \%$, ethanol $70 \%$, acetic acid) for $24 \mathrm{~h}$ and then they were dehydrated in 30, 40, and $60 \%$ ethanol. Needles were preserved in $70 \%$ ethanol (Krzymińska et al. 2001). Cross sections were hand cut with a scalpel using a medulla of Sambucus nigra.

A light microscope (Studar, PZO) was used for the observations of cross sections. The following morphological and anatomical needle traits were measured: height and width in the central part of a cross section, central cylinder height and width, height and width of five palisade parenchyma cells above the central cylinder, and distance between the vascular bundles. The Marcet's coefficient was calculated with the following formula: distance between the vascular bundles $\times$ needle width/needle height.

\section{Chlorophyll $\boldsymbol{a}$ fluorescence}

Chlorophyll $a$ fluorescence was measured in needles using Fluorescence Monitoring System (FMS 2, Hansatech, Norfolk, UK) operating in an online mode as it was earlier described in Robakowski (2005). Prior to measurements, needles were dark adapted for $30 \mathrm{~min}$ at ambient temperature, arranged tightly and stuck on a self-adhesive transparent tape and introduced into a factory-provided clip. Two or three needles were arranged such as to fill the entire aperture of the clip. The fiberoptics encased in a light-tight chamber was inserted onto the leaf clip and the needles were exposed to modulated measuring light of $0.05 \mu \mathrm{mol} \mathrm{m}{ }^{-2}$ $\mathrm{s}^{-1}$. After reading minimum fluorescence $F_{0}$, a saturating $0.7 \mathrm{~s}$ pulse of light $\left(\mathrm{PPFD}=15.3 \mathrm{mmol}\right.$ quanta $\left.\mathrm{m}^{-2} \mathrm{~s}^{-1}\right)$ was delivered to induce a maximum fluorescence $\left(F_{\mathrm{m}}\right)$. Maximum quantum yield of PSII photochemistry was calculated according to the formula: maximum quantum yield $=F_{\mathrm{v}} / F_{\mathrm{m}}$, where $\quad F_{\mathrm{v}}=F_{\mathrm{m}}-F_{0} \quad$ is variable fluorescence.

Subsequently, to generate light response curves of PSII quantum yield $\left(\Phi_{\text {PSII }}\right)$ needles in the clip were illuminated with actinic light using an inbuilt halogen lamp. The intensity of actinic light corresponding to values indicated by the software was measured prior to the experiment using a light sensor inserted in the leaf clip in the position of the needles. Up to six levels of actinic light were applied in the order of increasing intensity, and for each level, after a steady state fluorescence $\left(F_{\mathrm{s}}\right)$ was reached after 2-3.0 min, $0.7 \mathrm{~s}$ saturating pulse was delivered and maximum lightadapted fluorescence $\left(F_{\mathrm{m}}^{\prime}\right)$ was determined. Quantum yield of PSII was calculated by the built-in software as: $\Phi_{\text {PSII }}=\left(F_{\mathrm{m}}^{\prime}-F_{\mathrm{s}}\right) / F_{\mathrm{m}}^{\prime}$ (Genty et al. 1989). The course of fluorescence and all the measured parameters were monitored on the computer screen. At each actinic light level, non-photochemical quenching of fluorescence (NPQ) was calculated according to the formula: NPQ $=\left(F_{\mathrm{m}}-F_{\mathrm{m}}^{\prime}\right) /$ $F^{\prime}{ }_{\mathrm{m}}$ (Maxwell and Johnson 2000).

For each light level, the apparent rates of photosynthetic electron transport (ETR) were also calculated following the formula $\mathrm{ETR}=0.84 \times \Phi_{\mathrm{PSII}} \times \mathrm{PPFD} \times 0.5 \quad$ (Maxwell and Johnson 2000; Lüttge et al. 2003). Assumptions were made that the excitation energy is partitioned equally between the two photosystems (hence the factor 0.5; Maxwell and Johnson 2000) and that $84 \%$ of the incident radiation is absorbed by the photosystems (Rascher et al. 2000; Lüttge et al. 2003). However, leaf absorptance might slightly change with increasing needle age and self-shading in a tree crown (Zhang et al. 2008). Therefore, our ETR values should be considered as approximate.

The fluorescence measurements were taken at ambient temperature in laboratory, which was monitored during the fluorescence measurement using a thermocouple installed in the leaf clip.

\section{Analyses of nitrogen content in needles}

Nitrogen content was determined in needles used for gas exchange measurements. Total nitrogen content was determined with the Kjeldahl's method. The digestion of needle samples was conducted with a digestion system with sulfuric acid at $420{ }^{\circ} \mathrm{C}$ (Foss Tecator). Nitrogen was determined by distillation with water vapor in the apparatus of Parnas-Wagner. Nitrogen was analyzed spectrophotometrically following Kjedahl digestion at the Agricultural Chemistry Unit, the Poznan University of Life Sciences. Nitrogen content was expressed per needle area $\left(\mathrm{m}^{2}\right)$ or dry mass $(\mathrm{g})$. 


\section{Statistical analyses}

To compare the mean values of needle gas exchange and chlorophyll $a$ fluorescence parameters among the seven needle age classes, the analysis of covariance (ANCOVA) in General Linear Model (GLM) was applied $(P<0.05)$. The procedure of ANCOVA given in Stanisz (2007) was followed. In the ANCOVA design, current PPPFD was a continuous predictor variable; needle age class was categorical predictor variable; measured parameters were dependent variables. To assure the normality of distribution, homogeneity of variance and to linearize the model, the values of rPPFD in percent were transformed using the Bliss' function and the corresponding values of measured parameters were ln-transformed. First, homogeneity of slopes was checked to test whether the continuous and categorical predictors interacted in influencing the responses and, thus, whether the traditional ANCOVA design or the separate slope design was appropriate for modeling the effects of predictors. In all cases, the interaction was not statistically significant and, thus, the traditional ANCOVA was applied and followed by Tukey's a posteriori test $(P<0.05)$. The following model of ANCOVA was applied (Stanisz 2007): $y_{i j}=\mu+\alpha_{i}+$ $\beta\left(x_{i j}-x\right)+e_{i j}$, where $y_{i j}$ is the corrected values of dependent variable, $\mu$ is the general mean value, $\alpha_{i}$ is the effect of $i$-level of factor (needle age), $\beta$ is the coefficient of regression, $x_{i j}$ is the value of continuous predictor (light), $x$ is the mean value of continuous predictor, and $e_{i j}$ is the experimental error related to $\mathrm{i}$-factor and $\mathrm{j}$-observation. ANCOVA could not be used for the needle anatomical traits because the measured values did not have a normal distribution. Thus, non-parametric Kurskal-Wallis' test was used to compare the means among seven age classes of needles. To compare the mean values of rPPFD along the light gradient in the crown, the one-way analysis of variance was conducted (ANOVA) with needles' age as the independent variable and rPPFD as the dependent variable. Prior to analysis, rPPFD values were transformed using the Bliss' function. Normality of the data distribution was checked with the Shapiro-Wilk's test and homogeneity of variance with Levene's test. Linear or non-linear regression was used to determine the functional relationship between the needle age, LMA and the mean values or absolute values of the measured parameters.

\section{Results}

\section{Light gradient}

Mean values \pm SE of PPFD measured on cloudy day for each needle age class from 1- to 7-year-old needles were:
$21 \pm 2,18 \pm 2,16 \pm 2,12 \pm 2,9 \pm 2,6 \pm 1,4 \pm 1$. rPPFD linearly decreased from the youngest 1-year-old shoot increment towards the trunk (Fig. 1a). In one-way ANOVA, there were significant differences among rPPFD determined above a central part of each increment. rPPFD decreased from $78 \pm 5 \%$ at the 1-year-old needles to $13 \pm 3 \%$ at 6 -year-old needles. In Tukey's test, the first four needle age classes had the similar light environments which differed significantly from two oldest age classes.

\section{Needle structure}

Needle water content decreased linearly and LMA increased exponentially with needle age (Fig. 1b, c). A growing trend in LMA attained the highest mean value of $194 \pm 16 \mathrm{~g} \mathrm{~m}^{-2}$ in 4-year-old needles.

In needle cross section, the height/width ratio was highest in the oldest needles, but there was no significant relation between this ratio and needle age (Table 1). The central cylinder height increased, but cylinder width did not significantly change with needle age. Marcet's coefficient (the distance between the vascular bundles x needle cross section width/needle cross-section height) diminished with an increasing needle age (Table 1). The mean height of five palisade parenchyma cells increased and distance between the vascular bundles decreased with needle age (Table 1).

\section{Gas exchange and photosynthetic use efficiency}

Net $\mathrm{CO}_{2}$ assimilation rate declined exponentially with increasing needle age (Fig. 2a). It is noteworthy that the oldest needles showed a low $P$ by $2.0 \mu \mathrm{mol} \mathrm{CO} \mathrm{Cm}^{-2} \mathrm{~s}^{-1}$. The current-year needles had the highest $P$ by around $12.0 \mu \mathrm{mol} \mathrm{CO} \mathrm{CO}_{2} \mathrm{~m}^{-2} \mathrm{~s}^{-1}$. The 1-year-old needles differed in $P$ from the 6-year-old needles in Tukey's test. Needle transpiration $(E)$ and stomatal conductance $\left(g_{\mathrm{s}}\right)$ also declined exponentially with needle age, but in contrast to $P$, according to ANCOVA, these parameters were significantly modified by an acclimation to the current light conditions (Fig. 2b, c). Photosynthetic water use efficiency $(P / E)$ linearly decreased with needle age; however, there were no significant differences among the needle age classes (Fig. 2d). PNUE diminished exponentially with needle age and also there were no significant differences among the needle age classes (Fig. 3a). Subsequently, $P$, $E$ and $g_{\mathrm{s}}$ decreased exponentially with increasing LMA which increased with age (Figs. 1c, 4a-c).

\section{Needle nitrogen content}

Needle nitrogen concentration expressed per needle dry mass decreased linearly with age and there were significant 


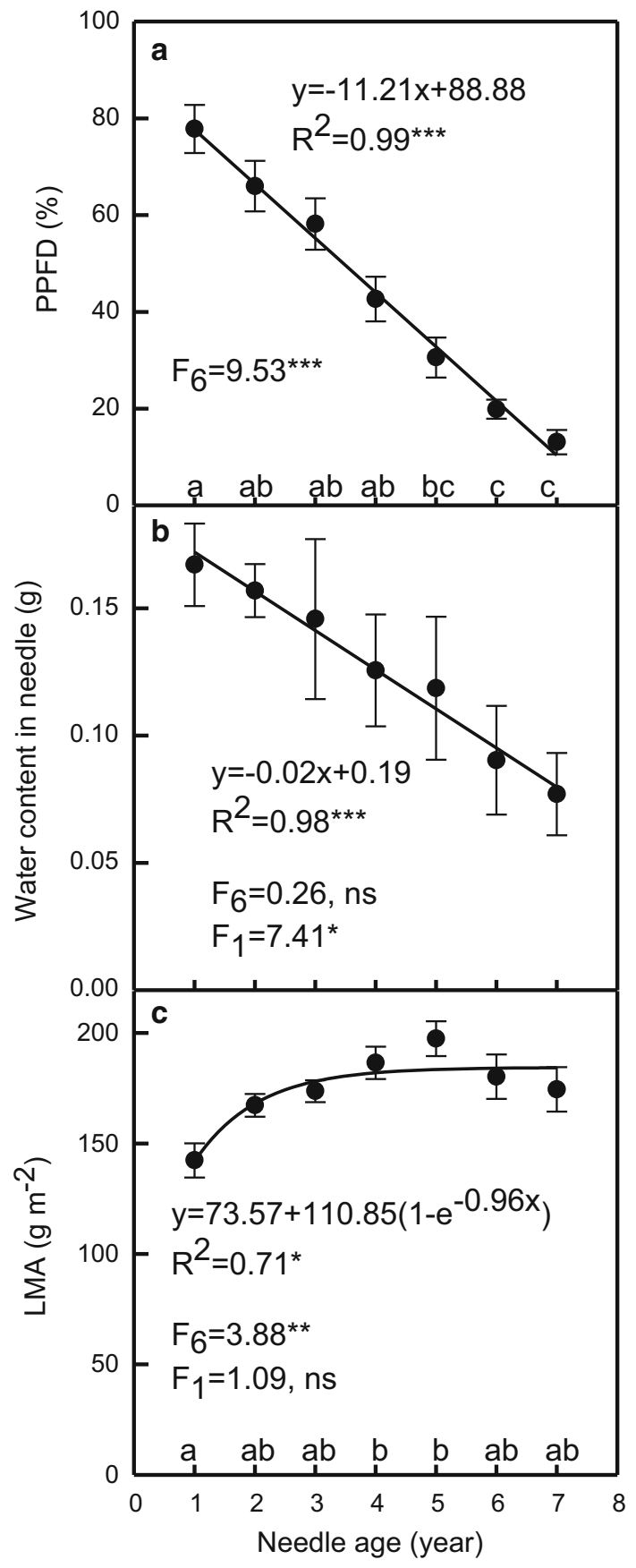

Fig. 1 The relative light levels above shoots' increments in a lower part of A. alba crown exposed to south (a), water content in needle (b), leaf mass-to-area ratio (LMA) (c) vs. age classes of A. alba needles (mean $\pm \mathrm{SE}, n=5$ ). In each plot, the equation of regression and coefficient of determination $\left(R^{2}\right)$ with probability are given. The values of Snedecor's function $(F)$ together with degrees of freedom in a lower index and probability (asterisks) obtained in one-way ANOVA (independent variable-age of needles) (a) or one-way ANCOVA (analysis of covariance) testing the needle age effect with light as the continuous predictor $(\mathbf{b}, \mathbf{c})$ are inserted in the plots. The different letters indicate statistically significant differences among the mean values obtained for needles' different age classes in Tukey's a posteriori test at the significance level $<0.05 . \quad P<0.001^{* * *}$, $0.001 \leq P<0.01^{* *}, 0.01 \leq P<0.05^{*}$

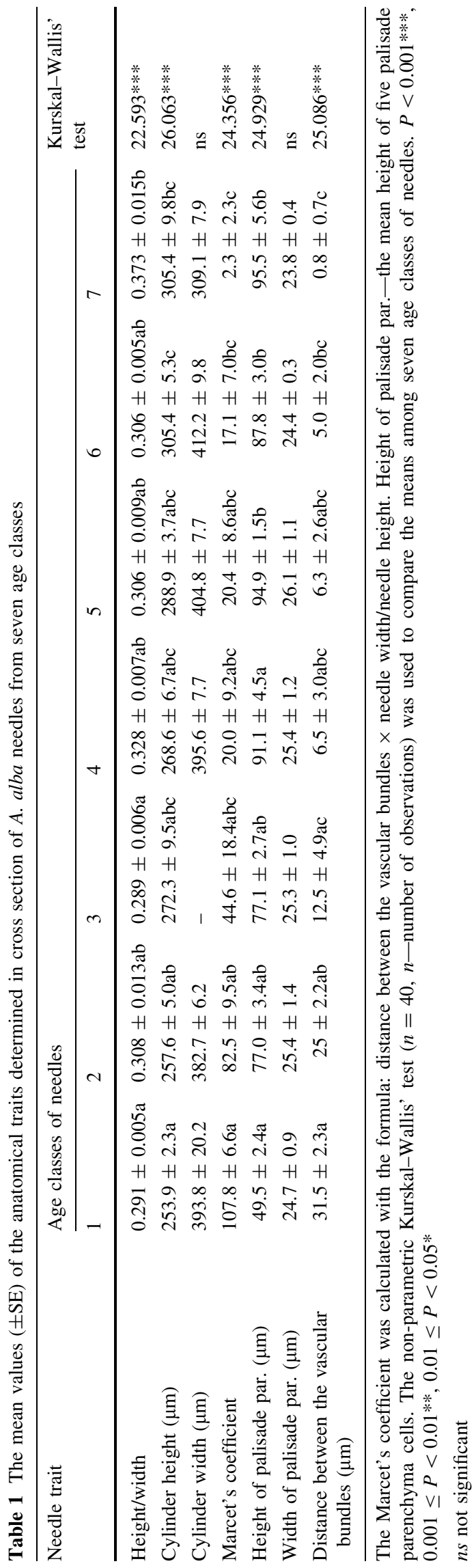


Fig. 2 Net $\mathrm{CO}_{2}$ assimilation rate per needle area (a), transpiration (b), stomatal conductance (c), photosynthetic water use efficiency (d) vs. age classes of $A$. alba needles (mean $\pm \mathrm{SE}, n=5$ ). The mean values of the photosynthetic parameters were fitted with decreasing exponential $(\mathbf{a}-\mathbf{c})$ or linear function (d). In each plot, the regression equation with $R^{2}$, probability in regression (asterisks) and the results of one-way ANCOVA followed by Tukey's a posteriori test are shown. $n s$ not significant. For further explanations, see Fig. 1 and "Materials and methods"

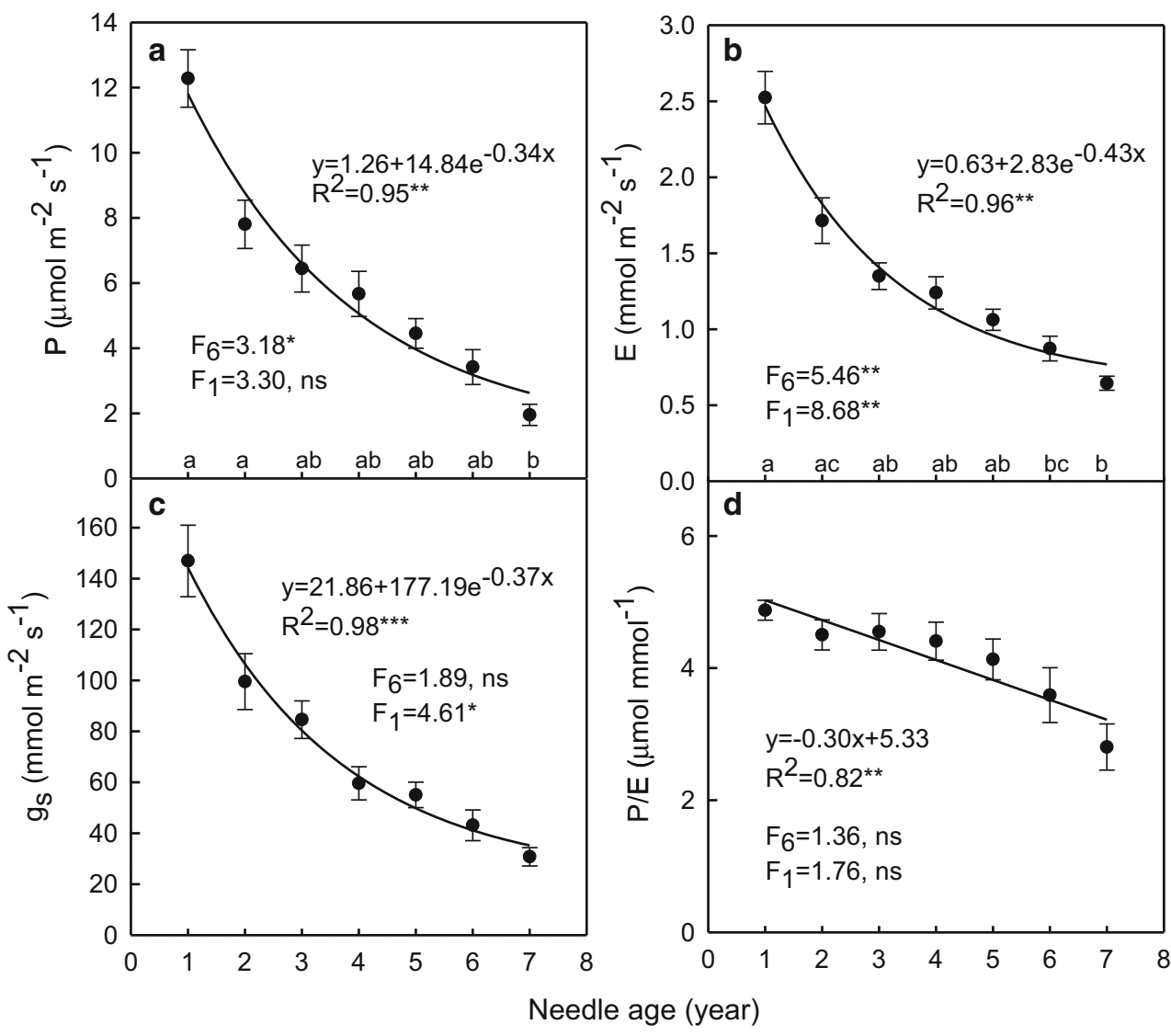

differences between the age classes (Fig. 3b). Nitrogen content per needle area was lowest in 6- and 7-year-old needles compared with the younger ones (Fig. 3c).

\section{Photochemistry}

The needle age and acclimation to light micro-environments in $A$. alba crown did not affect $F_{\mathrm{v}} / F_{\mathrm{m}}$ (the mean value of $F_{\mathrm{v}} / F_{\mathrm{m}}$ for all needle age classes $0.848 \pm 0.009$ ) (Fig. 5a). At low actinic light $\left(69 \mu \mathrm{mol} \mathrm{m}^{-2} \mathrm{~s}^{-1}\right), \Phi_{\text {PSII }}$ decreased slightly with age and it was lowest in 6-year-old needles (Fig. 5a). Under higher actinic light, $\Phi_{\mathrm{PSII}}$ attained maximal values in 2- and 3-year-old needles. The differences in $\Phi_{\mathrm{PSII}}$ among the needle age classes decreased with a greater PPFD of actinic light. 1-year-old needles showed the highest NPQ. NPQ decreased from the youngest needles to 2- and 3-year-old needles and then increased or remained stable depending on the actinic light level (Fig. 5b). There was no monotone trend in $\mathrm{ETR}_{\max }$ with increasing needle age. The 2-year-old needles showed this parameter higher than 6-year-old ones (Fig. 6a). The oldest and most shaded needles decreased remarkably $\Phi_{\text {PPFDsat }}$ compared with the younger ones growing in higher light (Fig. 6b).

\section{Discussion}

The structure and photosynthetic characteristics of A. alba needles have changed with age along the horizontal light gradient within the crown (Fig. 1a). A decrease in $P$ with needle age has been chiefly attributed to the age- and lightrelated structural adaptations in needles reflected by LMA and anatomical changes, and decrease in needle nitrogen concentration. We did not detect significant differences in stomatal conductance among the needle age classes despite a significant non-linear decreasing trend with age. This is in agreement with the results obtained by Warren (2006) for $P$. pinaster and Han et al. (2008) for P. densiflora. Our initial hypothesis has been supported by the significant increase in LMA (Fig. 1c), decrease in nitrogen content with needle age (Fig. 3b, c), and statistically significant relationships between LMA, $P$ and $g_{\mathrm{s}}$ (Fig. $4 \mathrm{a}, \mathrm{c}$ ). A decrease in $P$ with the foliage age has been reported by many authors (Freeland 1952; Weikert et al. 1989; Wang et al. 1995; Kitajima et al. 1997; Oleksyn et al. 1997; Jach and Ceulemans 2000; Crous and Ellsworth 2004; Warren 2006). However, the foliage age and the current light environment are correlated within a canopy and it is difficult to distinguish the age effect from the acclimation to 


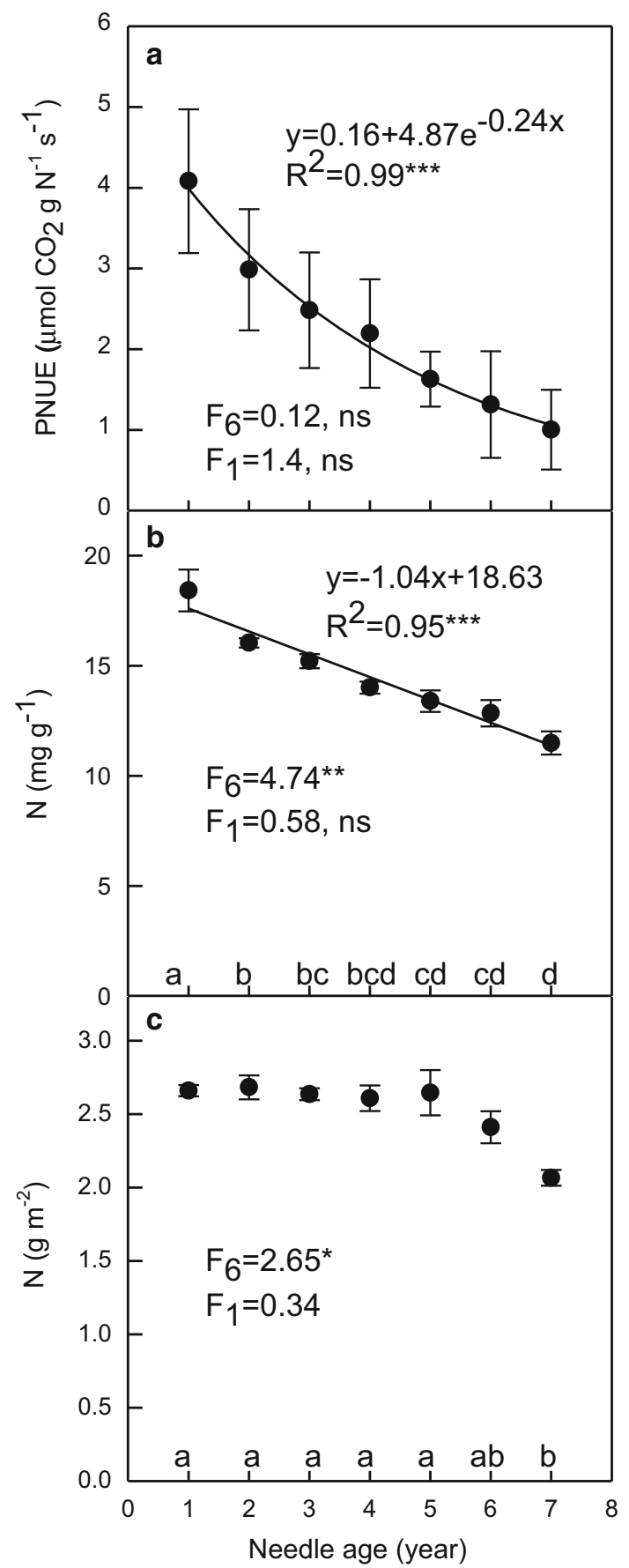

Fig. 3 Net $\mathrm{CO}_{2}$ assimilation rate per nitrogen content in needle (a), needle nitrogen concentration (b), nitrogen content per needles' area (c) vs. age classes of $A$. alba needles (mean $\pm \mathrm{SE}, n=5$ ). The results of the analysis of regression and ANCOVA followed by Tukey's a posteriori test are given. $R^{2}$ coefficient of determination, $F$ Snedecor's function together with degrees of freedom in a lower index and probability (asterisks)

current light conditions. Brooks et al. (1996) teased aging apart from light environment within the A. amabilis crown. Concomitantly with our findings, $P$ of $A$. amabilis decreased with both decreasing current light environment

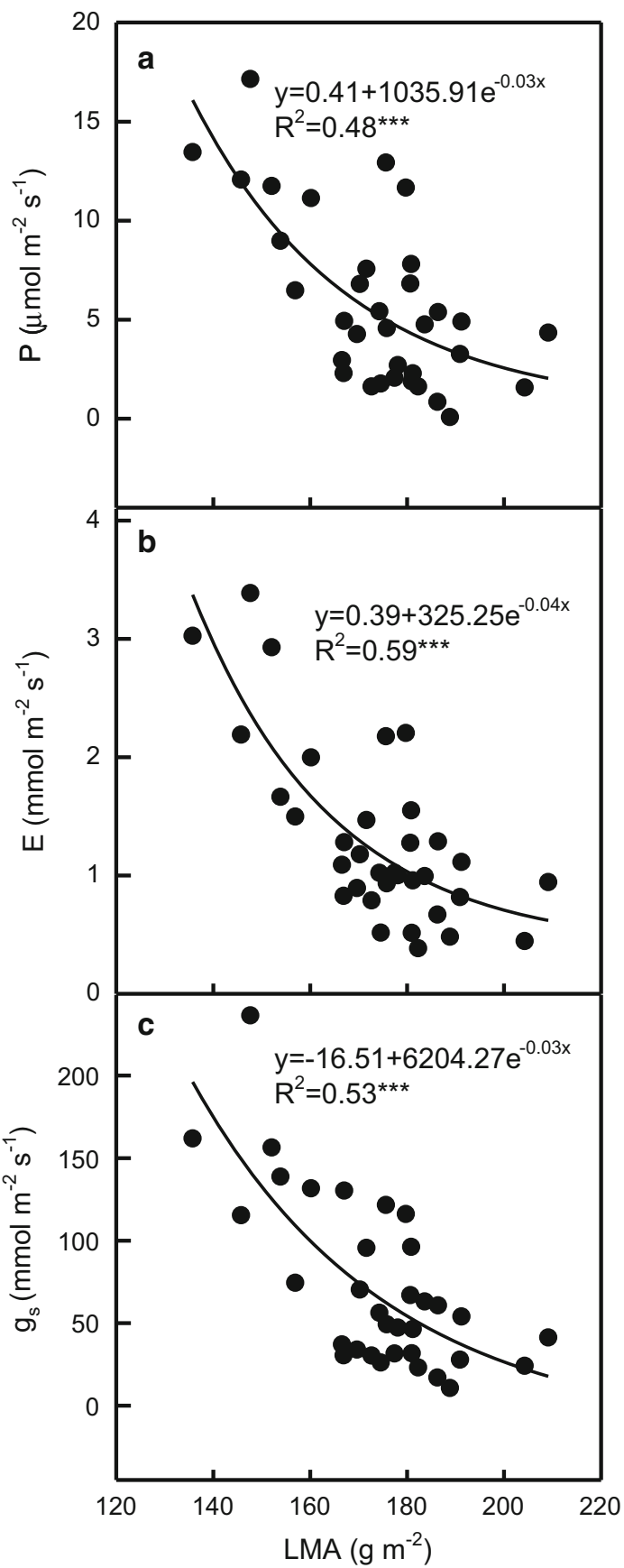

Fig. 4 Relationships between leaf mass-to-area ratio (LMA) and net $\mathrm{CO}_{2}$ assimilation rate per needles' area $\left(P_{\mathrm{A}}\right)(\mathbf{a})$, transpiration of needles $(E)(\mathbf{b})$, and stomatal conductance $\left(g_{\mathrm{s}}\right)(\mathbf{c})$ in $A$. alba crown. The regression equation and coefficient of determination $\left(R^{2}\right)$ with probability (asterisks) are given $(n=35)$

of the foliage and increasing foliage age from 1-year-old needles to 10-year-old ones. Our results obtained for A. alba confirmed the conclusion of Brooks et al. (1996) for $A$. amabilis that $P$ was most closely tied to light, but age also played a significant role.

In our study, an effect of senescence on photosynthesis and needle structure has been modified by the light micro- 
Fig. 5 Needles' age dependence of quantum yield of PSII photochemistry $\left(\Phi_{\mathrm{PSII}}\right)$ (a) and non-photochemical quenching of fluorescence (NPQ) (b) within an A. alba crown (mean $\pm \mathrm{SE}, n=5$ ). In a the values of quantum yield of PS II photochemistry

determined at PPFD $=0 \mu \mathrm{mol} \mathrm{m} \mathrm{m}^{-2} \mathrm{~s}^{-1}$ were maximum quantum yield of PS II photochemistry $\left(F_{\mathrm{v}} / F_{\mathrm{m}}\right)$. In the legends, the PPFD $\left(\mu \mathrm{mol} \mathrm{m} \mathrm{m}^{-2} \mathrm{~s}^{-1}\right.$ ) of actinic light prior to fluorescence measurements is given. The same letters indicate that the mean values do not differ significantly among the needle age classes within the given value of actinic light. Reprinted from: Robakowski (2011). Copyright 2011 by Nova Science Publishers, Inc., with permission from Nova Science Publishers, Inc.
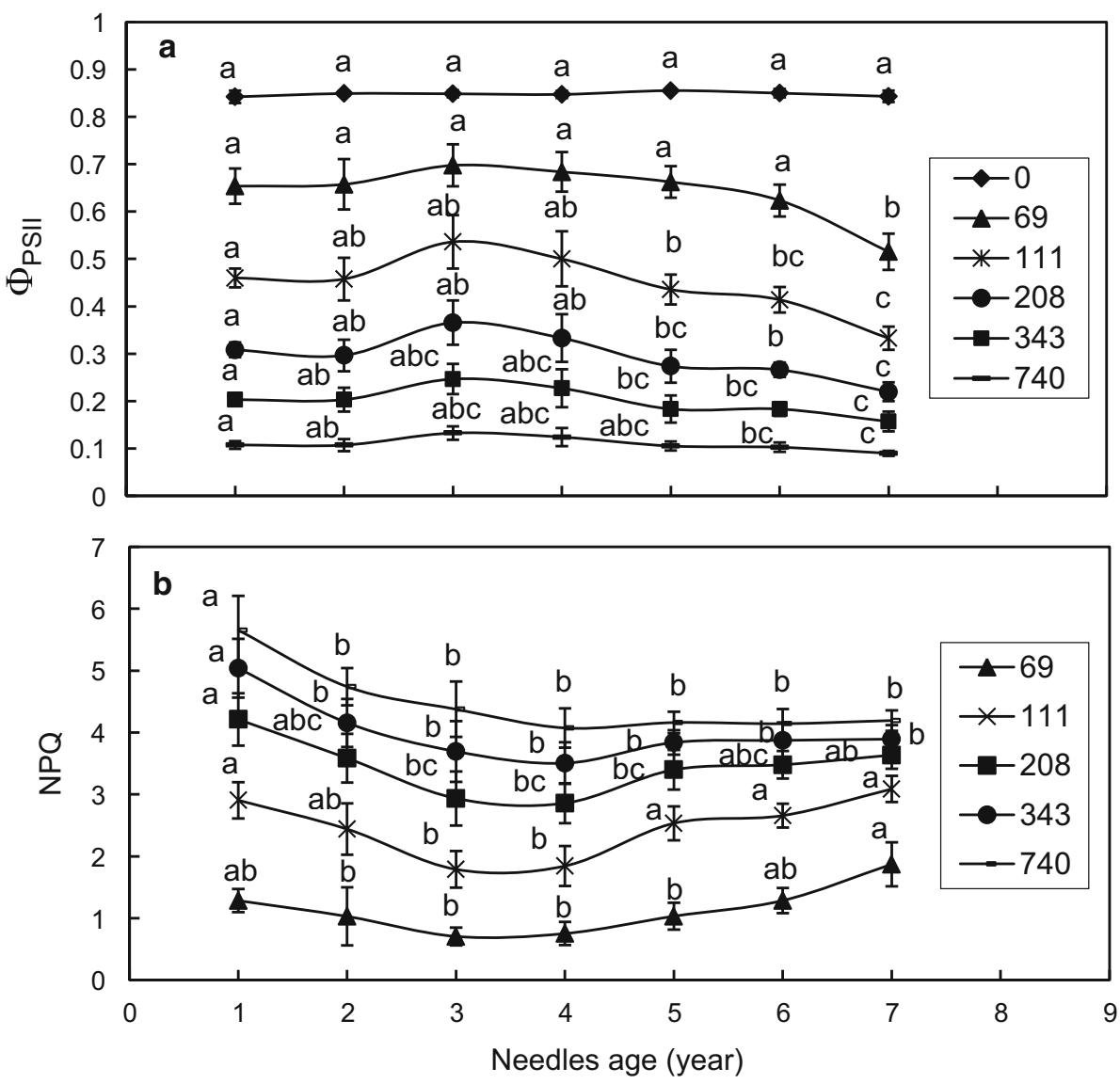

environments resulted from a self-shading of branches increasing from the 1-year-old shoot increment to the trunk. The size of A. alba needles decreased with their growing age which was associated with age-related changes in LMA and water content. The former increased from 1 -year-old needles to 4-year-old needles and stabilized in 5 and 6-year-old needles. In a similar experiment, LMA increased with needle age along a light gradient within a lower crown of $P$. densiflora (Han et al. 2008). The water content in needles of our study tree ranged from 53 for the current needles to $38 \%$ for the 6-year-old needles. The needle water content in the same age classes of $P$. heldreichii was 62 and 51\%, respectively (Oleksyn et al. 1997). In our study, $g_{s}$ decreased with an increasing needles' self-shading and was associated with a reduction of gas exchange intensity. Additionally, low water content in old needles of $A$. alba decreased transpiration and dissolved $\mathrm{CO}_{2}$ availability for photosynthesis.

In our experiment, nitrogen concentration in needles decreased, but when recalculated per needle area, it was less variable in function of needle age. As it was in case of $P$. densiflora, a decrease in A. alba needles nitrogen concentration was due to dilution (Han et al. 2008). In contrast to our results, in the A. amabilis foliage age explained little of the variation in leaf nitrogen once the effect of current light conditions was taken out (Brooks et al. 1996).

The structural needle adaptations (an increase in LMA and decrease in water content with needle age) observed with growing age together with anatomical modifications as increase in cylinder size, decrease in Marcet's coefficient, increase in height of palisade parenchyma, and decrease in distance between the vascular bundles have suggested that needle tissue density increased with age. Increasing needle tissue density has lowered $\mathrm{CO}_{2}$ concentration in intercellular spaces and probably increases mesophyll resistance to $\mathrm{CO}_{2}$ that leads to a reduction of PNUE with A. alba needle age (Niinemets et al. 2005, 2006). The other authors showed that mesophyll (internal) conductance to $\mathrm{CO}_{2}\left(g_{\mathrm{i}}\right)$ was correlated with the surface area of chloroplasts exposed to intercellular air space and $g_{\mathrm{i}}$ decreased with leaf age which might also be expected in our study tree (Hanba et al. 2001; Miyazawa and Terashima 2001).

Our results have supported to some extent the hypothesis that the reduction of $P$ results from lowering of photosynthetic resources use efficiency with needles' aging. 


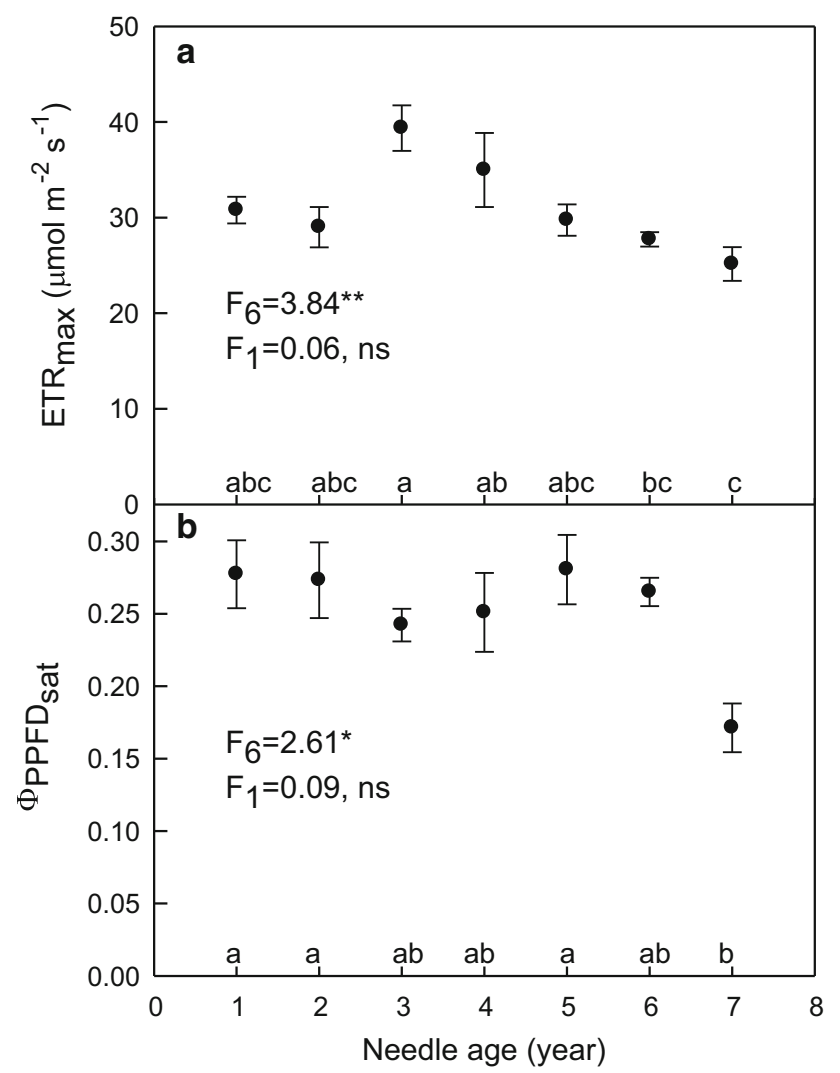

Fig. 6 Needles' age dependence of maximal apparent electron transfer rate $\left(\mathrm{ETR}_{\max }\right)(\mathbf{a})$, and quantum yield of PS II photochemistry at the saturation level of PPFD $\left(\Phi_{\text {PPFDsat }}\right)(\mathbf{b})$ in A. alba crown (mean $\pm \mathrm{SE}, n=5$ ). The results of ANCOVA followed by Tukey's test are shown. $F$ Snedecor's function together with degrees of freedom in a lower index and probability (asterisks). The different letters indicate statistically significant differences among the mean values obtained for needles of different age in Tukey's a posteriori test at $\alpha<0.05$

Although water and nitrogen use efficiency in photosynthesis of A. alba declined with increasing needle age, there were no significant differences among the needle age classes. This has suggested that the declining trends between $P / E$, PNUE and needle age classes resulted mainly from the changing light environment due to self-shading of branches.

In our study, when needle nitrogen concentration was expressed per needle dry mass, there was evidence that biochemical limitations of $P$ resulted at least partially from nitrogen translocation from old to young needles. However, nitrogen was monotone distributed per needle area unit in all age classes except for its remarkable decline in the oldest needles. This result has indicated that the most important age-related needle adaptations occurred in needle structure. Our conclusion has been supported by significant correlations between LMA, $P, E$, and $g_{\mathrm{s}}$ in $A$. alba needles. Concomitantly to our results, Jach and Ceulemans (2000) found that downregulation of photosynthesis was due to a reduction of $\mathrm{N}$ concentration on needle area basis when current and 1-year-old needles of $P$. sylvestris were compared. Nitrogen translocation from older to younger needles has been evidenced in conifers (Weikert et al. 1989; Nambiar and Fife 1991; Gielen et al. 2000).

In the present study, the needle age- and light-related reduction of $P$ was not in concert with optimal and stable maximum quantum yield of PSII photochemistry, which was not affected by aging and/or light gradient within the crown. This suggests that maintenance of optimal $F_{\mathrm{v}} / F_{\mathrm{m}}$ with increasing needle age has allowed old needles to absorb light and photosynthesize in the low-light environment of tree crown. In contrast to our results, in $P$. sylvestris $F_{\mathrm{v}} / F_{\mathrm{m}}$ of current-year needles was lower than that in 1-year-old needles (Gielen et al. 2000). High $F_{\mathrm{v}} / F_{\mathrm{m}}$ in all needle age classes of $A$. alba resulted from an acclimation to the low shade environment of growth and self-shading of branches, whereas a decrease in $F_{\mathrm{v}} / F_{\mathrm{m}}$ of current needles of $P$. sylvestris observed by Gielen et al. (2000) might be an acclimation to high light.

Our results indicated that a decrease in $P$ did not follow changes in needle photochemical performance with age. $\Phi_{\text {PSII }}$ and NPQ were non-linearly related to the micro-light environments associated with the foliage age classes. The highest $\Phi_{\mathrm{PSII}}, \mathrm{ETR}_{\max }$ and lowest NPQ were in 2- and 3 -year-old needles suggesting that these parameters have been controlled by light conditions along the horizontal gradient within the crown. These needles had the most suitable light environment for photosynthesis compared with current needles exposed to high light causing PSII downregulation and older ones which had lower water content and nitrogen concentration. Even an important reduction of nitrogen concentration in the oldest needles did not substantially affect their $F_{\mathrm{v}} / F_{\mathrm{m}}$ suggesting that in strong self-shading, nitrogen was translocated to the lightharvesting complexes and photochemistry, probably at the expense of ribulose-1,5-bisphosphate carboxylase/oxygenase concentration. However, our observation has not been corroborated by the results of Warren (2006) who found that in $P$. pinaster Rubisco concentration was low in current-year needles and did not show any trend with increasing needle age. Interestingly, in accordance with variation of ETR $_{\max }$ observed in our experiment, maximum electron transfer rate $\left(J_{\max }\right)$ obtained from $\mathrm{A} / \mathrm{C}_{\mathrm{i}}$ curves did not significantly decrease with needle age in $P$. densiflora and $P$. pinaster (Han et al. 2008; Warren 2006).

The results of the present study have suggested that there is a mechanism controlling the relationship between efficiency of light and dark photosynthetic processes along the needle age and shade gradients in A. alba crown. Old needles have fully functional photochemistry that allowed them to absorb and use low light in a tree crown for photosynthesis. Simultaneously, in old needles, an energy sink 
of net $\mathrm{CO}_{2}$ assimilation is substantially reduced by modifications of needle structure, reduction of stomatal conductance, and nitrogen concentration. These changes can lead to decrease in maximum carboxylation rate $\left(V_{\mathrm{cmax}}\right)$, and Rubisco activity ( $V_{\text {cmax }} /$ Rubisco) (Niinemets 2002; Warren 2006). The trade-off between photosynthetic processes in the dark and photochemistry occurring with needle aging along the light gradient in a tree crown can be better elucidated with the study of nitrogen partitioning into different photosynthetic processes.

Author contribution statement PR conceived the study and wrote the first version of the manuscript. PR and EB conducted all measurements and laboratory work, analyzed data and edited the manuscript.

Open Access This article is distributed under the terms of the Creative Commons Attribution 4.0 International License (http://crea tivecommons.org/licenses/by/4.0/), which permits unrestricted use, distribution, and reproduction in any medium, provided you give appropriate credit to the original author(s) and the source, provide a link to the Creative Commons license, and indicate if changes were made.

\section{References}

Adams WW III, Demmig-Adams B (1994) Carotenoid composition and down regulation of photosystem II in three conifer species during the winter. Physiol Plant 92:451-458

Adams WW III, Zarter CR, Ebbert V, Demmig-Adams B (2004) Photoprotective strategies of overwintering evergreens. Bioscience 54(1):41-49

Anderson MJ, Park Y-I, Chow WS (1997) Photoinactivation and photoprotection of photosystem II in nature. Physiol Plant 100:214-223

Brooks JR, Sprugel DG, Hinckley TM (1996) The effects of light acclimation during and after foliage expansion on photosynthesis of Abies amabilis foliage within the canopy. Oecologica 107:21-32. doi:10.1017/CBO9781107415324.004

Crous KY, Ellsworth DS (2004) Canopy position affects photosynthetic adjustments to long-term elevated $\mathrm{CO}_{2}$ concentration (FACE) in aging needles in a mature Pinus taeda forest. Tree Physiol 24:961-970

Freeland RO (1952) Effect of age of leaves upon the rate of photosynthesis in some conifers. Plant Physiol 27:685-690

Genty B, Briantais J-M, Baker NR (1989) The relationship between the quantum yield of photosynthetic electron transport and quenching of chlorophyll fluorescence. Biochim Biophys Acta 990:87-92

Gielen B, Jach ME, Ceulemans R (2000) Effects of season, needle age, and elevated atmospheric $\mathrm{CO}_{2}$ on chlorophyll fluorescence parameters and needle nitrogen concentration in Scots pine (Pinus sylvestris). Photosynthetica 38:13-21

Givinish TJ (2002) Adaptive significance of evergreen vs. deciduous leaves: solving the triple paradox. Silva Fenn 36:703-743

Han Q, Kawasaki T, Nakano T, Chiba Y (2008) Leaf-age effects on seasonal variability in photosynthetic parameters and its relationships with leaf mass per area and leaf nitrogen concentration within a Pinus densiflora crown. Tree Physiol 28:551-558

Hanba YT, Miyazawa S-I, Kogami H, Terashima I (2001) Effects of leaf age on internal $\mathrm{CO}_{2}$ transfer conductance and photosynthesis in tree species having different types of shoot phenology. Aust J Plant Physiol 28(11):1075-1084

Jach ME, Ceulemans R (2000) Effects of season, needle age and elevated atmospheric $\mathrm{CO}_{2}$ on photosynthesis in Scots pine (Pinus sylvestris). Tree Physiol 20:145-157

Kayama M, Kitaoka S, Wang W et al (2007) Needle longevity, photosynthetic rate and nitrogen concentration of eight spruce taxa planted in northern Japan. Tree Physiol 27:1585-1593

Kitajima K, Mulkey SS, Wright SJ (1997) Decline of photosynthetic capacity with leaf age in relation to leaf longevities for five tropical canopy tree species. Am J Bot 84:702-708

Kivimäenpää M, Sutinen S (2007) Microscopic structure of Scots pine (Pinus sylvestris (L.)) needles during ageing and autumnal senescence. Trees Struct Funct 21:645-659. doi:10.1007/ s00468-007-0157-8

Krzymińska A, Zenkteler E, Czekalski M (2001) Budowa anatomiczna sadzonek pędowych różaneczników i powstawanie $\mathrm{w}$ nich korzeni przybyszowych. [Anatomy of Rhododendrons cuttings and formation of their roots.]. Roczniki Akademii Rolniczej w Poznaniu CCCXXXIV Bot 4:137-140 (in Polish)

Lüttge U, Berg A, Fetene M, Nauke P, Dirk P, Beck E (2003) Comparative characterization of photosynthetic performance and water relations of native trees and exotic plantation trees in Ethiopian forest. Trees 17:40-50

Maier ChA, Johnsen KH, Butnor J, Kress LW, Anderson PH (2002) Branch growth and gas exchange in 13-year-old loblolly pine (Pinus taeda) trees in response to elevated carbon dioxide concentration and fertilization. Tree Physiol 22:1093-1106

Maxwell K, Johnson GN (2000) Chlorophyll fluorescence-a practical guide. J Exp Bot 51:659-668

Miyazawa S-I, Terashima I (2001) Slow development of leaf photosynthesis in an evergreen broad-leaved tree, Castanopsis sieboldii: relationships between leaf anatomical characteristics and photosynthetic rate. Plant Cell Environ 24:279-291. doi:10. 1046/j.1365-3040.2001.00682.x

Nambiar EKS, Fife DN (1991) Nutrient retranslocation in temperate conifers. Tree Physiol 9:185-207. doi:10.1093/treephys/9.1-2. 185

Niinemets Ü (2002) Stomatal conductance alone does not explain the decline in foliar photosynthetic rates with increasing tree age and size in Picea abies and Pinus sylvestris. Tree Physiol 22:515-535

Niinemets Ü, Cescatti A, Rodeghiero M, Tosens T (2005) Leaf internal diffusion conductance limits photosynthesis more strongly in older leaves of Mediterranean evergreen broadleaved species. Plant Cell Environ 28:1552-1566. doi:10.1111/j. 1365-3040.2005.01392.x

Niinemets Ü, Cescatti A, Rodeghiero M, Tosens T (2006) Complex adjustments of photosynthetic potentials and internal diffusion conductance to current and previous light availabilities and leaf age in Mediterranean evergreen species Quercus ilex. Plant Cell Environ 29:1159-1178. doi:10.1111/j.1365-3040.2006.01499.x

Oleksyn J, Tjoelker MG, Lorenc-Plucinska G et al (1997) Needle $\mathrm{CO} 2$ exchange, structure and defense traits in relation to needle age in Pinus heldreichii Christ-a relict of tertiary flora. Trees Struct Funct 12:82-89. doi:10.1007/s004680050125

Rascher U, Liebieg M, Lüttge U (2000) Evaluation of instant lightresponse curves of chlorophyll fluorescence parameters obtained with a portable chlorophyll fluorometer on site in the field. Plant Cell Environ 23:1397-1405

Reich PB, Oleksyn J, Modrzynski J, Tjoelker MG (1996) Evidence that longer needle retention of spruce and pine populations at high elevations and high latitudes is largely a phenotypic response. Tree Physiol 16:643-647

Reich PB, Tjoelker MG, Walters MB et al (1998) Close association of RGR, leaf and root morphology, seed mass and shade tolerance 
in seedlings of nine boreal tree species grown in high and low light. Funct Ecol 12:327-338. doi:10.1046/j.1365-2435.1998. 00208.x

Robakowski P (2005) Susceptibility to low-temperature photoinhibition in three conifers differing in successional status. Tree Physiol 25:1151-1160

Robakowski P (2011) Photochemical processes in needles of overwintering evergreen conifers. In: Maes KJ, Willems JM (eds) Photochemistry UV/VIS spectroscopy, photochemical reactions and photosynthesis. Nova Science Publishers, New York, pp 333-351

Stanisz A (2007) Przystępny kurs statystyki z zastosowaniem Statistica PL na przykładach z medycyny. T. 2, Modele liniowe i nieliniowe. [Accessible course of statistica with the application of Statistica PL on examples from medicine, vol 2, Linear and non-linear models.] Statsoft Polska Sp. z o.o. (in Polish)

Szymura TH (2009) Concentration of elements in silver fir (Abies alba Mill.) needles as a function of needles' age. Trees 23:211-217. doi:10.1007/s00468-008-0268-x

Wang K, Kellomäki S, Laitinen K (1995) Effects of needle age, longterm temperature and $\mathrm{CO}_{2}$ treatments on the photosynthesis of
Scots pine. Tree Physiol 15:211-218. doi:10.1093/treephys/15.4. 211

Warren CR (2006) Why does photosynthesis decrease with needle age in Pinus pinaster? Trees Struct Funct 20:157-164. doi:10.1007/ s00468-005-0021-7

Weikert RM, Wedler M, Lippert M et al (1989) Photosynthetic performance, chloroplast pigments, and mineral content of various needle age classes of spruce (Picea abies) with and without the new flush: an experimental approach for analysing forest decline phenomena. Trees 3:161-172. doi:10.1007/ BF00226652

Wright IJ, Reich PB, Westoby M et al (2004) The worldwide leaf economics spectrum. Nature 428:821-827

Wyka T, Robakowski P, Zytkowiak R (2008) Leaf age as a factor in anatomical and physiological acclimative responses of Taxus baccata L. needles to contrasting irradiance environments. Photosynth Res 95:87-99

Zhang Y, Chen JM, Miller JR, Noland TL (2008) Retrieving chlorophyll content in conifer needles from hyperspectral measurements. Can J Remote Sens 34(3):296-310 